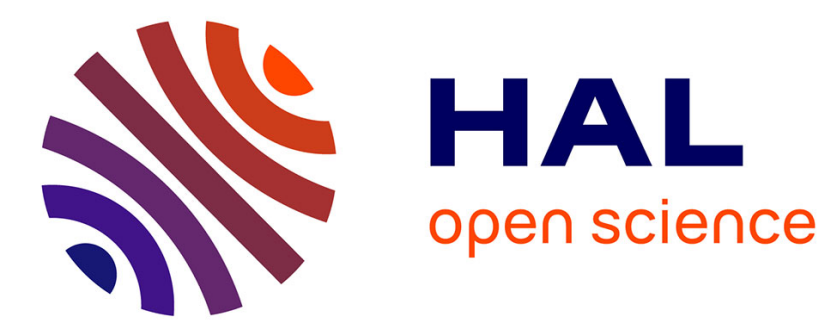

\title{
Physical Modeling Of Extreme Waves Propagating From The Open Sea To The Coastal Zone
}

Iskander Abroug, Nizar Abcha, Armelle Jarno, François Marin

\section{To cite this version:}

Iskander Abroug, Nizar Abcha, Armelle Jarno, François Marin. Physical Modeling Of Extreme Waves Propagating From The Open Sea To The Coastal Zone. Sixth International Conference on Estuaries and Coasts (ICEC-2018), Aug 2018, Caen, France. hal-02423371

\section{HAL Id: hal-02423371 \\ https://hal.science/hal-02423371}

Submitted on 24 Dec 2019

HAL is a multi-disciplinary open access archive for the deposit and dissemination of scientific research documents, whether they are published or not. The documents may come from teaching and research institutions in France or abroad, or from public or private research centers.
L'archive ouverte pluridisciplinaire HAL, est destinée au dépôt et à la diffusion de documents scientifiques de niveau recherche, publiés ou non, émanant des établissements d'enseignement et de recherche français ou étrangers, des laboratoires publics ou privés. 


\title{
Physical Modeling Of Extreme Waves Propagating From The Open Sea To The Coastal Zone
}

\author{
Iskander Abroug*, Nizar Abcha \\ Normandie Univ, UNICAEN, UNIROUEN, CNRS, M2C, 14000 Caen, France \\ Armelle Jarno, François Marin \\ Normandie Univ, UNIHAVRE, CNRS, LOMC, 76600 Le Havre, France
}

\begin{abstract}
The propagation of solitary waves above an horizontal bottom and a sloping bottom is considered in this paper. Experiments are carried out in a wave flume above smooth beds. The solitary waves are generated with a piston-type wave maker, using an impulsive mechanism (Marin, F et al. (2005)). Close to the generation zone, the profile contains elevation and depression components. These depressions are attached to the main solitary wave during the propagation along the flume. The energy damping along the horizontal and sloping bottoms (Zhang, $\mathrm{C}$ et al. (2010)), the wave height variation in the shoaling zone, the breaking modes and the runup height are investigated. It is shown that spatiotemporal diagrams are adapted for tracking the evolution of solitary waves propagating from a horizontal bed to a sloping bed (Chang, L et al. (2014)). The breaking parameters are obtained using high resolution cameras. Present results are in good agreement with earlier studies (Hsiao, $\mathrm{S}$ et al 2008). A new formula is proposed for the estimation of runup height.
\end{abstract}

Key words: Extreme waves; Solitary waves; Shoaling; Energy damping; Breaking waves; Runup.

Notation

* Corresponding author. Email: iskander.abroug@unicaen.fr 
$A_{0}=$ Amplitude of solitary wave 3 meter form the wave maker, $\mathrm{m}$.

$A_{1}, A_{2}=$ Wave heights for water depths $\mathrm{h}_{1}$ and $\mathrm{h}_{2}$, $\mathrm{m}$.

$A_{b}=$ Breaking height, $\mathrm{m}$.

$A_{s}=$ Solitary wave amplitude, $\mathrm{m}$

$A_{t}=$ Amplitude of solitary wave at the toe of the beach, $\mathrm{m}$.

$C_{g r}=d \omega / d k=$ Group velocity corresponding to the main solitary wave, $\mathrm{m} . \mathrm{s}^{-1}$

$E=$ Energy on a unit length in the direction transversal in the direction of wave propagation, J.m $\mathrm{m}^{-1}$

$<\eta>=$ mean water level, $\mathrm{m}$

$\rho=$ Water density, $1 \mathrm{~g} . \mathrm{cm}^{-3}$

\section{Introduction}

Giant waves or extreme waves correspond to waves of very high amplitude. These waves may be accompanied by deep troughs that may appear before or after the highest peak. This type of wave has been a mythical phenomenon in the marine environment for centuries. Extreme waves occur in basins of different depths with and without current. One of the firsts who observed this phenomenon was the captain and naval officer of an expedition in 1826 Dumont d'Urville, who reported about 30 meters high waves. These waves may be due to a large variety of physical mechanisms (Kharif C., Pelinovsky, 2003). Among others, solitary waves may be considered. The first description of these waves was made by John Russel (1834) who observed a boat trained rapidly by a pair of horses in a channel at Hermiston. When the boat was suddenly stopped, Russel noted that a wave having the shape of a lonely high altitude wave was propagating along the channel without any evident change in shape. (J.S. Russel., 1845). Boussinesq (1871) derived a mathematical expression for the solitary wave profile generated on a horizontal, rectangular channel. Solitary waves are traditionally used as tsunami waves approximation because of the hydrodynamic similarity between them (e.g. Shih-Chun Hsiao et al., (2010)). Some laboratory studies have considered the shoaling (Camfield et al. (1969); Kishi et al. (1966)) and the runup of solitary waves (e.g. Synolakis. (1987); Li and Raichlen. (2001); Zelt et al. (1991)). Gradual damping was investigated by Keulegan (1948) and Daily et al. (1952). Synolakis and Skjelbreia (1993) investigated the amplitude evolution of breaking solitary waves on a plane beach. They found that the complete amplitude evolution can be divided into four regions (especially in the case of smooth slopes). Synolakis (1991) confirmed mathematically that, the solitary wave amplitude $g=$ Acceleration of gravity, $\mathrm{m} . \mathrm{s}^{-2}$

$h_{0}=$ Stillwater depth, $\mathrm{m}$

$h_{b}=$ Breaking depth, $\mathrm{m}$.

$L_{0}=$ Wave length scale, $\mathrm{m}$.

$R=$ Runup height, $\mathrm{m}$.

$S_{0}=$ Slope parameter.

$T=$ Duration of impulse, $\mathrm{s}$

$\beta=0.04=$ Slope, rad.

$\varepsilon=A_{0} / h_{0}=$ Non linearity parameter (1).

$\varepsilon^{\prime}=A_{t} / h_{0}=$ Non linearity parameter (2).

$\eta=$ free surface elevation, $\mathrm{m}$

before breaking, can be perfectly modelled by Green's law.

Waves with abnormally high amplitudes do not occur only on high seas, but also in the coastal zone. A lot of studies have considered these waves in the open ocean; however, they have received little attention in the coastal zone. The physical processes involved in the transformation of these waves from the open sea to the coastal zone are poorly understood, despite the significant impact these waves may have on the coasts, such as overtopping, material damages, and erosion (Strusińska-Correia. and Oumeraci (2012), Marin et al. (2005)). The aim of the present work is to bring a contribution to the study of these processes from physical modeling.

The paper is organized as follows. Section 2 describes the experimental set-up. Results are presented in Section 3. The shoaling, wave energy, wave breaking, and runup are considered. Section 4 is devoted to discussion and conclusions.

\section{Experimental set-up}

Experiments are carried out in a wave flume of the coastal and continental morphodynamcis Laboratory at Caen University, France. The flume is $20 \mathrm{~m}$ length and $0.8 \mathrm{~m}$ width. An Edinburgh design Ltd piston-type paddle is used to generate waves. Waves propagate through uniform water depth to a $1 / 25$ sloping smooth beach, at the other

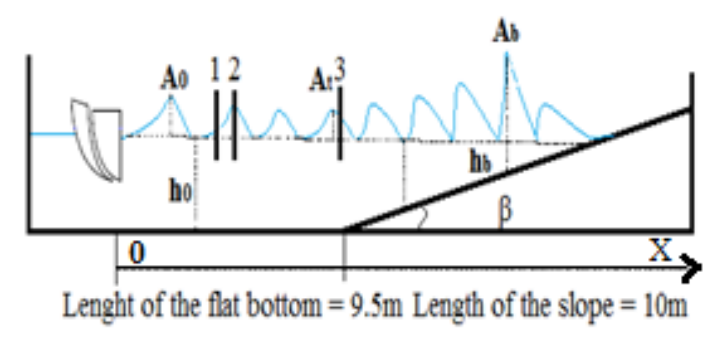

Figure 1. Sketch of the experimental setup 
end of the flume

The flume side walls are made of glass. The beach toe is located $9,5 \mathrm{~m}$ from the wave maker. Flume bottom is elevated $1.15 \mathrm{~m}$ from the ground to facilitate the visualizations from the side glasses. Free surface elevations are measured by resistive waves gauges. Mainly, three wave gauges are used. Gauges 1 and 2 are used to plot the space-time diagram STD (more details in the next section) and gauge 3 is used for the measure of the free surface elevation at the toe of the beach. Waves of different spectrum and amplitudes are generated in the flume under conditions of deep water and shallow water. To generate surface waves in the flume, a computer controlled wavemaker is used. A schematic sketch of this experimental setup is shown in Figure 1.

In order to confirm the repeatability of present tests, two surface elevation measurements at the same location are conducted. Differences were less than $2 \%$. However, tests are less repeatable once the wave breaks down due to the entrapped compressed air present during the breaking process.

The governing parameters include the still water depth $\mathrm{h}_{0}$, the local water depth $\mathrm{h}$, the initial solitary wave amplitude $\mathrm{A}_{0}$, the local solitary wave amplitude $A$, the free surface elevation $\eta$, the wave amplitude at breaking $A_{b}$, the corresponding water depth $h_{b}$ and run-up height $R$.

A high-speed camera is used for tracking the wave features while propagating in the breaking and swash zones. The camera is operating with a $30 \mathrm{~Hz}$ acquisition frequency.

\section{Results}

\section{a. Wave profile}

Figure 2 shows a comparison between the experimental and theoretical profiles of a solitary wave. A nonlinear solution obtained by Boussinesq approximation has been used for the theoretical profile, for $\varepsilon=A_{0} / h_{0}=0.24$. A very good agreement is obtained. We can note that the experimental profile exhibits a very weak dispersive tail.

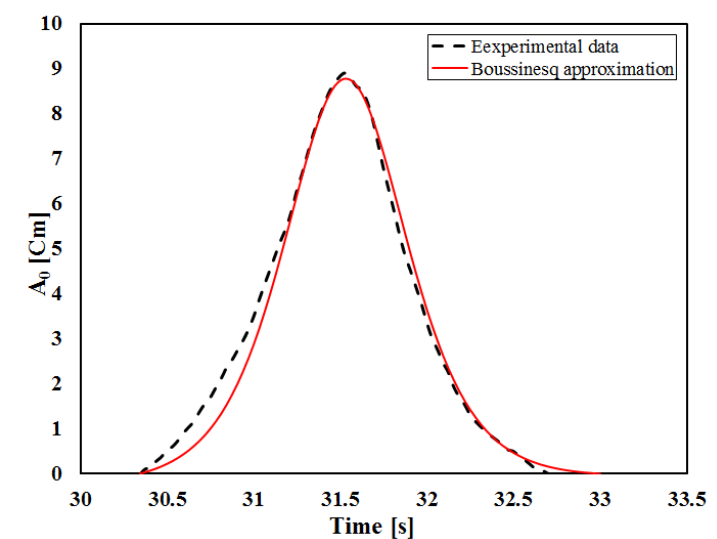

Figure 2. Comparison between theoretical and experimental solitary wave form
In order to generate solitary waves, Goring (1979) used derived Boussinesq's first order solution

$$
\begin{gathered}
\eta(\xi)=\eta(x-V t) \\
\eta(\xi)=A_{s} \cosh ^{-2}\left(\sqrt{\frac{3 A_{s}}{4 h_{0}^{3}}}(x-V t)\right) \\
V_{s}=V_{0}\left(1+\frac{A_{s}}{2 h}\right), \text { with } V_{0}=\sqrt{g h}
\end{gathered}
$$

Where $A_{s}$ is the solitary wave amplitude, $V_{s}$ the theoretical wave velocity, $A_{0}$, and $A_{t}$ the amplitudes of solitary wave, 3 meters from the wave maker and at the toe of the beach, respectively. A satisfactory agreement is obtained between (2) and experimental wave velocities, as shown in Figure 3.

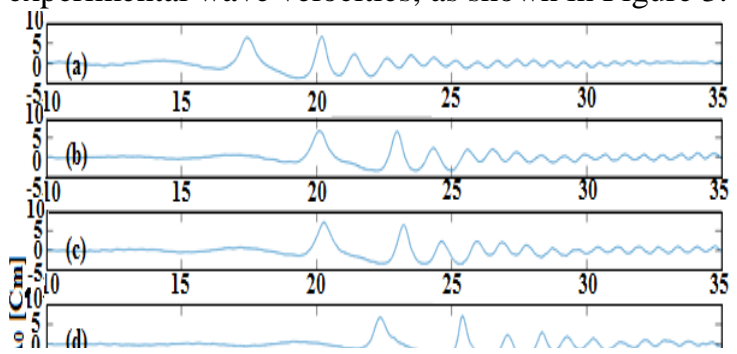

Figure 3. Zoom on the main solitary wave; $A_{0} / h_{0}=0.28$ (13 $\mathrm{m}$ up to $16.7 \mathrm{~m}$ from the wave maker)

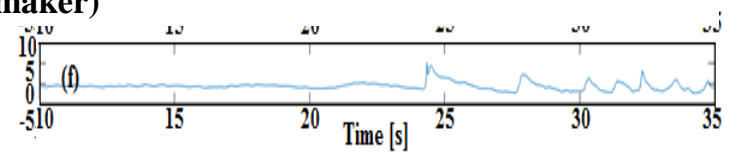

Figure 5. Comnarison between theoretical (Ea. Figure 4. Evolution of the solitary wave $\left(A_{0} / h_{0}=0.28\right)$ with time: instantaneous signals at different distances from the wave maker; a: $6 \mathrm{~m}$; b: $8 \mathrm{~m}$; c: $10 \mathrm{~m}$; e: $12 \mathrm{~m}$; f: $14 \mathrm{~m}$

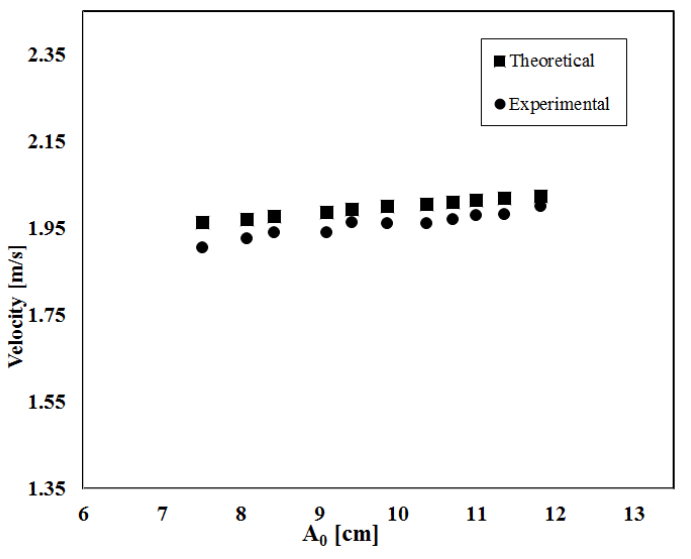

b. Shoaling and energy

\section{Shoaling}

The free surface elevations were recorded at different locations along the flume with resistive wave gauges (gauges 1 and 2, Figure 1). Free 
surface instantaneous components can be overlaid chronologically at regular time intervals in order to plot space-time diagrams. Gauge 1 is fixed $3 \mathrm{~m}$ from the wave maker and used as temporal reference and gauge 2 is moved $10 \mathrm{~cm}$ after each acquisition. The information obtained along the flume from the resistive probes are compiled in a matrix describing the evolution of free surface elevation along the flume.

An example of spatio-temporal diagram is shown in Figure 4. In this diagram, the evolution of the amplitude of the wave, and the width of the solitary wave along the channel are well described. A very weak dispersive tail is observed behind the main solitary wave.

The solitary wave has a symmetric profile along the flat bottom. When it reaches the slope, the wave height increases and the shape becomes more and more asymmetric (Figure 5).

Synolakis and Skjelbreia (1993) mentioned that the amplitude evolution of a solitary wave on a sloping beach can be divided into four zones for plunging and spilling breaking waves. They called the zones gradual shoaling and rapid shoaling before the breaking point, and rapid decay and gradual decay inside the surf zone. In particular, in each zone the maximum local wave elevation can be adequately described by a simple power-law-type formula as a function of spatial location with a normalization of breaking water depth for convenience (Synolakis and Skjelbreia, 1993).

In this study the measured amplitudes amplifications are compared to the following shoaling relationship based on linear long waves (Green's law):

$$
\frac{A_{1}}{A_{2}}=\left(\frac{h_{1}}{h_{2}}\right)^{-1 / 4}
$$

where $A_{1}$ and $A_{2}$ are wave amplitude for the water depths $h_{1}$ and $h_{2}$, respectively.

Figure 6 shows that Green's law describes satisfactorily the variation of the amplitude along the slope.

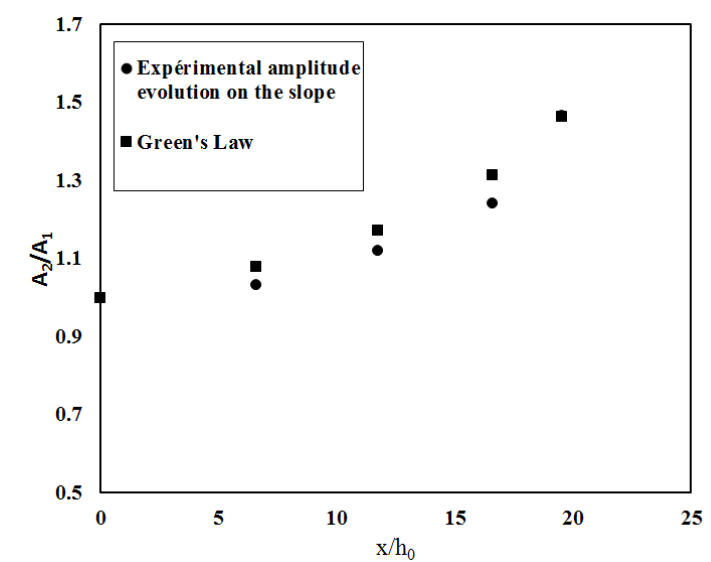

Figure 6. Amplitude evolution on the slope for $\varepsilon^{\prime}=A_{t} / h_{0}=0.26$ and comparisons with Green's Law
When the crest velocity exceeds the solitary wave celerity, the wave breaks. By zooming in on the STD, position and height of breaking point can be identified. In practice it is better to zoom in as much as possible and detect the brutal change in amplitude (Figure 4). The STD is a way to get a good overview of what is happening along the flume, before and after shoaling. Otherwise, the video visualization gives a good resolution of the local water surface elevation (30 fps). Therefore, when investigating breaking height and distance, the camera is a better solution. Table 1 summarizes comparisons between STD and video visualization results. It appears that breaking heights are slightly different when STD is used. This is due to the air

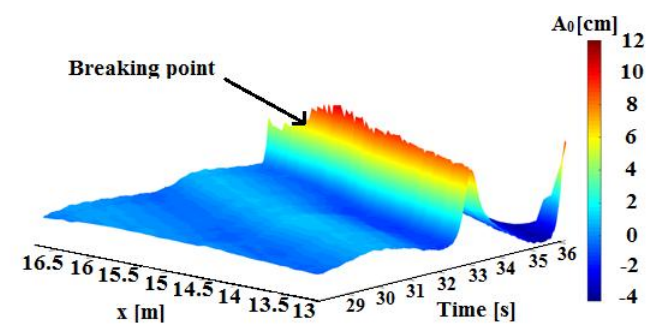

entrainment phenomenon generated by breaking waves which can have an influence on the signal given by the gauge at the breaking point $\left(\mathrm{x}_{\mathrm{b}}\right)$.

\section{Energy}

The waves energy is investigated on the flat bottom and on the slope. Equation 4 (Tian el al., 2010) is used to calculate the energy of the solitary wave on the flat bottom for a given position:

$$
\left.E=\frac{\rho g}{2} C_{g r} \int(\eta-<\eta>)^{2} d t\right)
$$

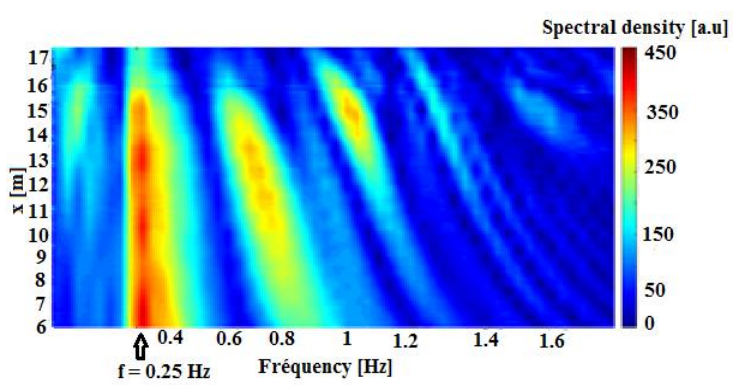

where $C_{g r}=\frac{d \omega}{d k}$ is the group velocity corresponding to the main solitary wave, $g$ the acceleration of gravity, $\rho$ the water density, $T$ the duration of impulse, $\eta$ and $\langle\eta\rangle$ the free surface displacement and mean water level, respectively. 
Figure 7. Zoom on the spectrogram of complete solitary wave signal $(6 \mathrm{~m}$ up to $16.7 \mathrm{~m}$ from the wave maker); $A_{0} / h=0.28$ (a.u: arbitrary units)

Table 1. Height and distance of breaking; comparisons between STD and camera measurements

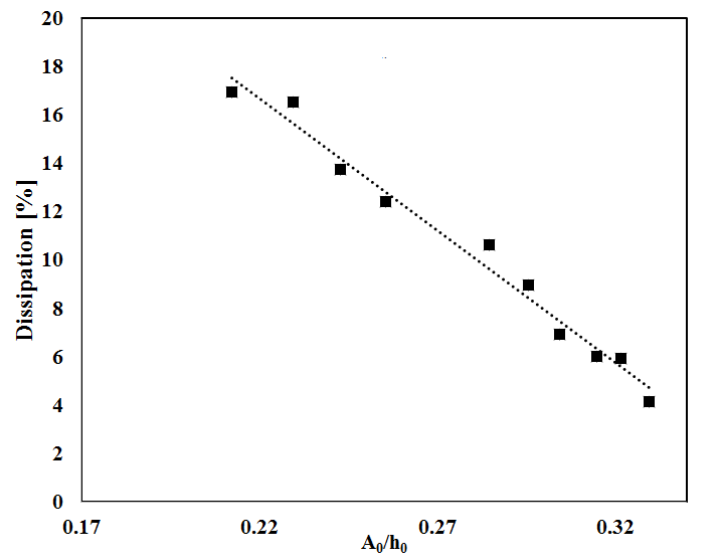

Figure 8. Variation of the amplitude dissipation factor with $\varepsilon=\mathrm{A}_{0} / \mathrm{h}_{0}$ on the flat bottom (from $3 \mathrm{~m}$ up to $9.5 \mathrm{~m}$ )

Figure 8 shows that the amplitude dissipation factor $\left(\mathrm{D}=\left(\frac{\mathrm{D}_{3}-\mathrm{D}_{9.5}}{\mathrm{D}_{3}}\right)\right)$, which describes amplitude evolution along $6.5 \mathrm{~m}$ on the flat bottom, decreases linearly for increasing values of $\mathrm{A}_{0} / \mathrm{h}_{0}$ from $17 \%$ for the lowest solitary wave amplitude up to $4 \%$ for the highest wave amplitude. This has also been experimentally obtained by Ippen and Kulin (1954). When the solitary wave reaches the slope and before breaking, the wave celerity decreases, the wave height increases and the total energy is approximately conserved. (Ying li and Fredric Raichlen 2002).

The energy spectral density (Figure 7) shows that the spectral density $\left(f_{\text {excitation }}=0.25 \mathrm{~Hz}\right)$ of the main solitary wave $\left(\mathrm{A}_{0} / \mathrm{h}_{0}=0.28\right)$ is conserved during the wave propagation until wave breaking which occurs approximately for $x=15 \mathrm{~m}$. A second band of energy is identified as the spectral density of the wave generated by the piston pullback. In term of intensity this band and small bands of higher frequencies $(1.2 \mathrm{~Hz}$ and $1.4 \mathrm{~Hz})$ are less strong than the main band. Therefore, " super harmonics" waves do not have a significant impact on the shoaling phenomenon and on the runup of the main solitary wave. Moreover, higher frequency waves travel slower than lower frequency waves and reach the shore after the solitary wave (Orszaghova et al. (2014). The band for frequencies around $0.85 \mathrm{~Hz}$ is slightly inclined when compared to the main spectrum. When propagated along the flume, this band tends to get closer to the solitary wave spectrum. This inclination is due to the instable form of the wave generated by the pullback of the piston. Otherwise, it is also shown that a band around $0.15 \mathrm{~Hz}$, which corresponds to low frequency waves, appears especially when the bed slope starts. These subharmonic waves propagate

\begin{tabular}{|l|l|c|l|l|}
\hline$\varepsilon^{\prime}$ & $\begin{array}{l}\mathrm{X}_{\mathrm{b}}[\mathrm{c} \\
\mathrm{m}] \\
(\mathrm{Cam} \\
\mathrm{era})\end{array}$ & $\begin{array}{c}\mathrm{X}_{\mathrm{b}}[\mathrm{cm}] \\
(\mathrm{STD})\end{array}$ & $\begin{array}{l}\mathrm{A}_{\mathrm{b}}[\mathrm{cm}] \\
(\text { Camer } \\
\mathrm{a})\end{array}$ & $\begin{array}{l}\mathrm{A}_{\mathrm{b}}[\mathrm{cm}] \\
(\mathrm{STD})\end{array}$ \\
\hline 0.21 & 587 & {$[580 ; 590]$} & 9.32 & 8.91 \\
\hline 0.24 & 558 & {$[540 ; 550]$} & 10.31 & 10.01 \\
\hline 0.27 & 532 & {$[530 ; 540]$} & 11.15 & 10.70 \\
\hline 0.31 & 514 & {$[510 ; 520]$} & 11.66 & 11.15 \\
\hline
\end{tabular}

along the flume. They are amplified when reaching the slope (shoaling zone). However, in term of spectral density intensity the energy is approximately three times lower than the energy of the main solitary wave. Therefore, we consider that subharmonic wave effect is not significant.

\section{Breaking}

Grilli et al. (1997) and Synolakis (1987) defined a breaking criterion. They proposed two thresholds, (5) and (6) are used to predict if the incident solitary wave is a breaking wave or not.

$$
\begin{gathered}
\varepsilon^{\prime}=\frac{A_{t}}{h_{0}}=16,9 \beta^{2}=0.027 \\
\varepsilon^{\prime}=\frac{A_{t}}{h_{0}}=0.818 \beta^{\frac{10}{9}}=0.023
\end{gathered}
$$

Where $\beta=0.04$ is the beach slope, and $\varepsilon^{\prime}=\mathrm{A}_{\mathrm{t}} / \mathrm{h}_{0}$ is a nonlinearity parameter. For the present study, the nonlinearity parameter is in the range $0.10<\varepsilon^{\prime}<0.27$. Therefore, all waves are breaking waves for present tests.

Grilli et al. (1997) and Yasuda et al. (1992) introduced empirical parameters for slope parameter (Equations 7 and 8):

$$
\begin{gathered}
S_{0}=\frac{\beta L_{0}}{h_{0}}=1.521 \frac{\beta}{\sqrt{\varepsilon^{\prime}}} \\
\xi_{s}=\frac{\beta}{\varepsilon^{\prime} 0.4}
\end{gathered}
$$

$\mathrm{S}_{0}$ is the slope parameter, and $\mathrm{L}_{0}$ is a characteristic horizontal length scale for the initial wave (Grilli et al. (1997) for more details about $\mathrm{L}_{0}$ ).

According to Grilli et al. (1997), $\mathrm{S}_{0}$ in equation 7 has a $99.9 \%$ correlation with $\xi_{\text {s }}$ introduced by Yasuda et al. (1992).

$\mathrm{S}_{0}$ and $\varepsilon^{\prime}$ are used to determine breaking type:

$$
\begin{array}{ll}
\text { - } & \mathrm{S}_{0}<0,025 \text { : Surging breaking } \\
\text { - } & 0,025<\mathrm{S}_{0}<0,3 \text { : Plunging breaking } \\
\text { - } & 3<\mathrm{S}_{0}<3,7 \text { : Spilling breaking }
\end{array}
$$

According to these criteria, breaking in this study can be considered as plunging breaking for all solitary wave amplitudes $\left(0.06 \leq \mathrm{S}_{0} \leq 0.09\right)$. It is validated by direct observations.

Using a speed camera of high resolution, we are able to follow the evolution of the free surface in space, and to identify the position of the breaking 
point. Figure 9 illustrates snapshots of breaking process for a solitary wave with $A_{0} / h_{0}=0.28$. The vertical tangent to the free surface corresponds to the spatial position of the breaking wave

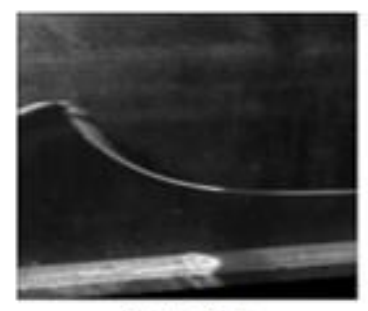

a) : $t=0 \mathrm{~s}$

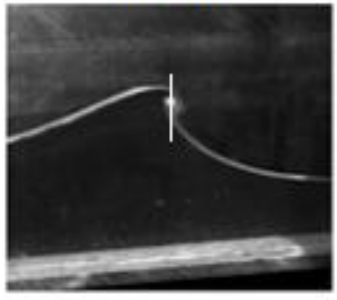

c) : $t=0.4 \mathrm{~s}$, Breaking
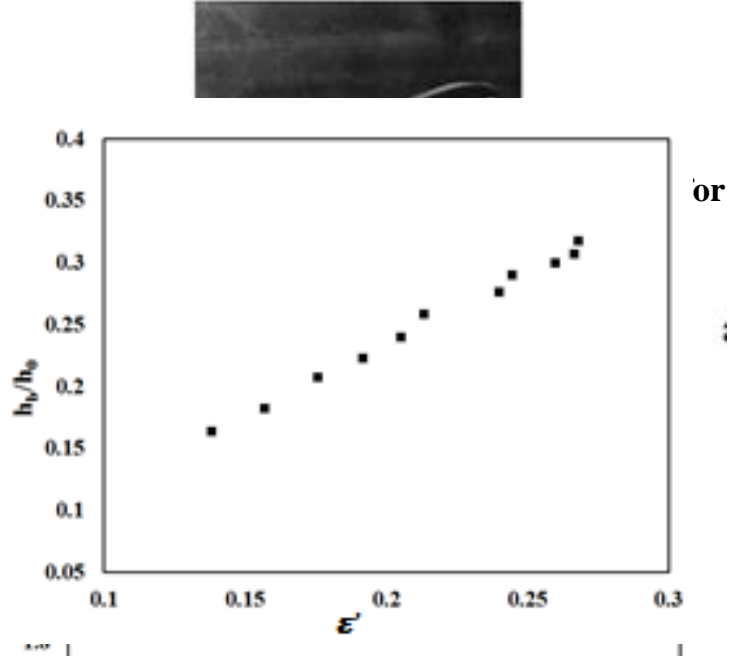

Figure 10. Breaking distance evolution with $\varepsilon$ '

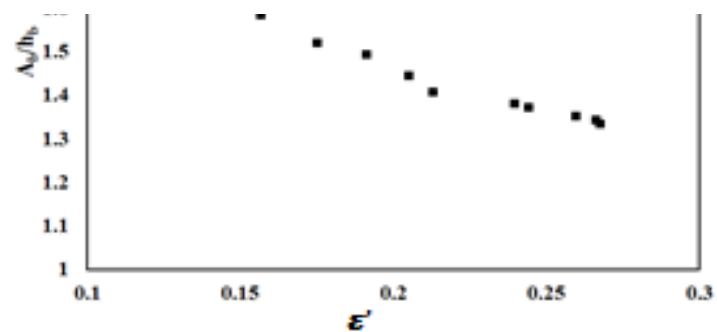

Figure 9. Variation of the breaking height with $\boldsymbol{\varepsilon}^{\prime}$
The variation of the dimensionless breaking height with the dimensionless amplitude of the wave at the beginning of the slope is depicted in Figure 10. The relative breaking height is found to decrease for increasing values of $\boldsymbol{\varepsilon}^{\prime}=\mathrm{A}_{\mathrm{t}} / \mathrm{h}_{0}$, as suggested by these authors.

$$
\frac{A_{b}}{h_{b}}=0,841 e^{6.421 S_{0}}
$$

Grilli et al. (1997) have derived (9) using a least square method for a wide range of slopes (between $\beta=1 / 100$ and $\beta=1 / 8$ ). Present data has a $99.25 \%$ correlation with equation (9).

In Figure 11, the variation of the dimensionless water depth at the breaking point $\mathrm{h}_{\mathrm{b}} / \mathrm{h}_{0}$ is plotted as a function of $A_{t} / h_{0}$. Grilli et al. (1997) and Hafsteinsson et al. (2017) suggested respectively (10) and (11) for water depths determination.

$$
\begin{gathered}
\frac{h_{b}}{h_{0}}=\frac{0.149}{\left(\frac{S_{0}}{\varepsilon \prime}\right) 0.523} \\
\frac{h_{b}}{h_{0}}=-0,25\left[1+\ln \left(\varepsilon^{\prime-1} \tan \beta\right)\right]
\end{gathered}
$$

Present data has $99.33 \%$ and $98.71 \%$ correlation with (10) and (11) respectively. Therefore (10) is slightly better when investigating breaking depths.

\section{c. Runup}

Measured runup heights are compared with literature on Figure 12. This figure shows that, for the same $\varepsilon$ ', runup heights are higher for steeper slopes. Present results $(\beta=1 / 25)$ clearly show that the runup height increases for increasing values of $\varepsilon^{\prime}=A_{t} / h_{0}$. This results from the large energy of large solitary wave amplitudes.

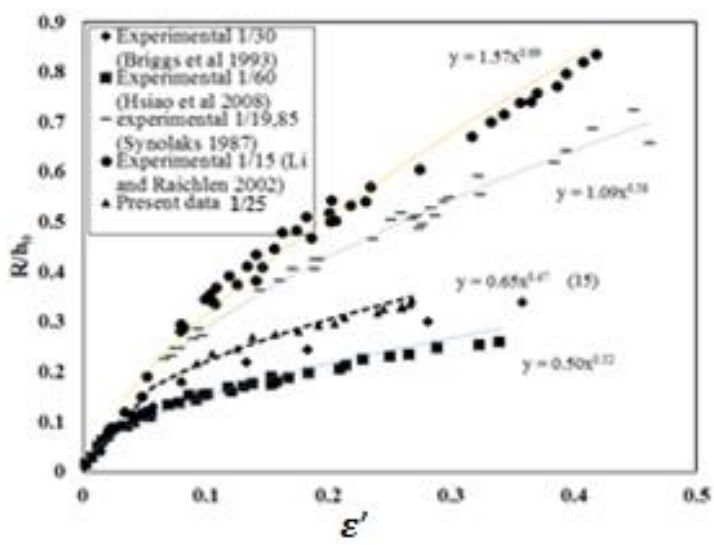

Figure 12. Normalized runup variation with $\varepsilon$ '

Synolakis (1987) suggested the following empirical formula:

$\frac{R}{h_{0}}=1,0957 \varepsilon^{\prime 0,5816}$

Where $\mathrm{R}$ is the maximal run-up amplitude. This formula is exclusively for the slope that Synolakis used $(\beta=1: 19.85)$. Numerous studies have suggested several empirical formulas similar to that of Synolakis; in the form $\frac{R}{h}=a \varepsilon^{\prime b}, a$ and $b$ being parameters depending on the slope. 


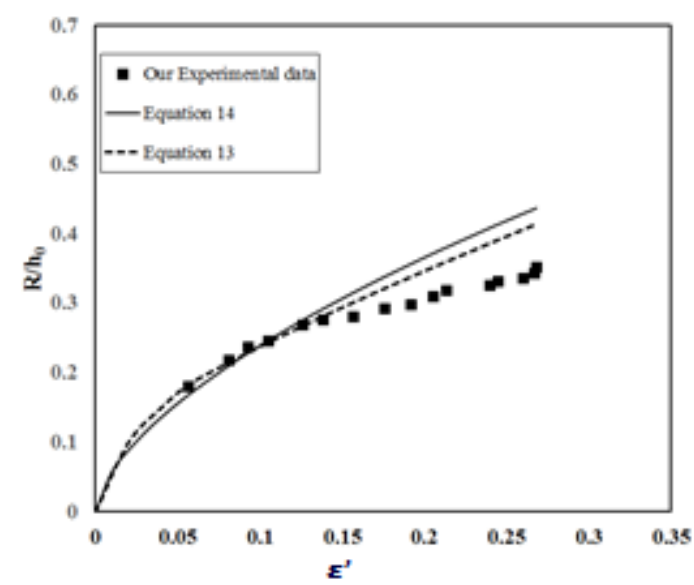

Figure 13. Maximal run-up amplitude comparisons with equation 13 and equation 14

Hughes (2004) employed the momentum flux parameter to predict maximum runup:

$\frac{R}{h_{0}}=(1.39-0.027 \cot (\beta))\left(\frac{M_{F}}{\rho g h_{0}}\right)^{1 / 2}$

Where $\frac{M_{f}}{\rho g h_{0}}$, is the wave momentum flux parameter (This parameter is easily determined in Hughes (2004)). He noted that this equation gives reasonable predictions as far as the slopes are between $1 / 10$ and $1 / 30$ for $\varepsilon<0.25$.

Hsiao et al in 2008 suggested a simple predictive model based on the nonlinear least-square algorithm:

$\frac{R}{h_{0}}=7.712 \cot (\beta)^{-0,632}\left(\sin \left(\varepsilon^{\prime}\right)\right)^{0,618}$

Equation 13 and 14 predict well maximum runup amplitude for low waves (up to $\varepsilon^{\prime}=0.15$ )), whereas they over estimate it for $\varepsilon$ ' higher than 0.2 (Figure 13). It was mentioned in Hsiao et al. (2008) that Equation 14 contains no physical meaning, but it gives reasonable maximum runup predictions for a wide range of slopes. It is the case when equation 16 is compared to Briggs et al. (1993) who have worked with a 1/30 slope. Agreements are less good when $\varepsilon$ ' becomes higher than 0.20 .

From the present data, an empirical formula is suggested for the estimation of runup height, for a 1:25 slope:

$$
\frac{R}{h_{0}}=0.65 \varepsilon^{\prime 0.47}
$$

Figures 14 and 15 show that waves with high amplitude are characterized by high values of the time for runup saturation defined as the time needed by the wave to reach maximum runup.

Runup velocity is determined using high speed camera. A video recording with $30 \mathrm{~Hz}$ acquisition frequency is used for each solitary wave. Furthermore, each solitary wave is identified by only one runup saturation height.

Briggs et al. (1993) have plotted the maximal runup amplitude versus an energy-based parameter using runup speed to reach the associated runup saturation. They suggested a linear relationship that can be used to predict the runup saturation for a known runup velocity.

$$
\frac{R}{h_{0}}=0,0013+0,7755 \times V
$$

In Figure (16), the maximal run-up amplitude versus runup velocities is plotted. Runup speed for 1:25 slope is greater than for a 1:30 slope. This is not true for small wave amplitudes (mainly nonbreaking waves). This is due to the energy dissipation which is more important for low amplitudes.

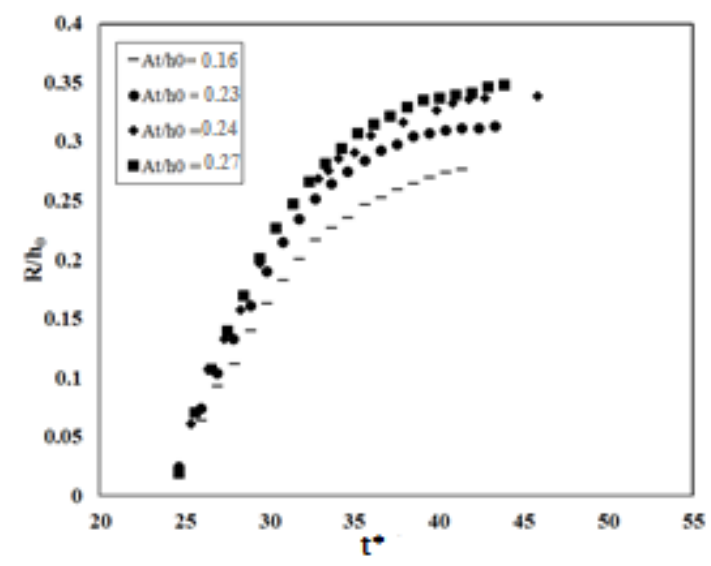

Figure 14. Runup evolution versus dimensionlesstime for 4 different waves $\left(t^{*}=\right.$ $t \sqrt{\left.\frac{g}{h_{0}}\right)}$

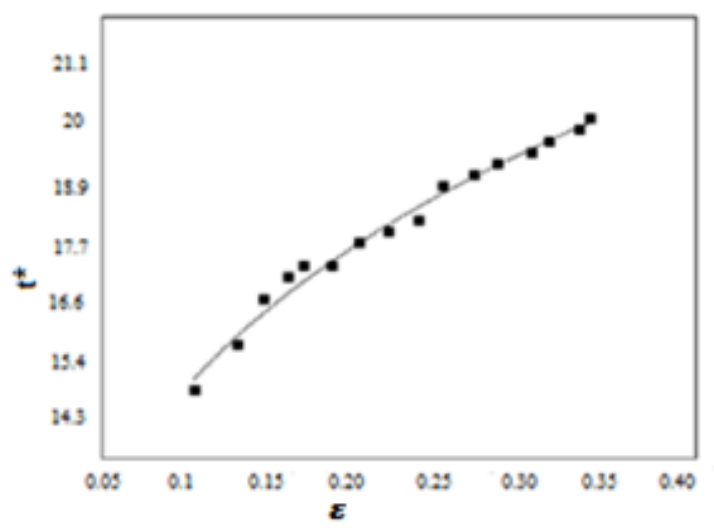

Figure 15. Dimensionless time of runup saturation versus $\varepsilon\left(t^{*}=t \sqrt{\frac{g}{h_{0}}}\right)$ 


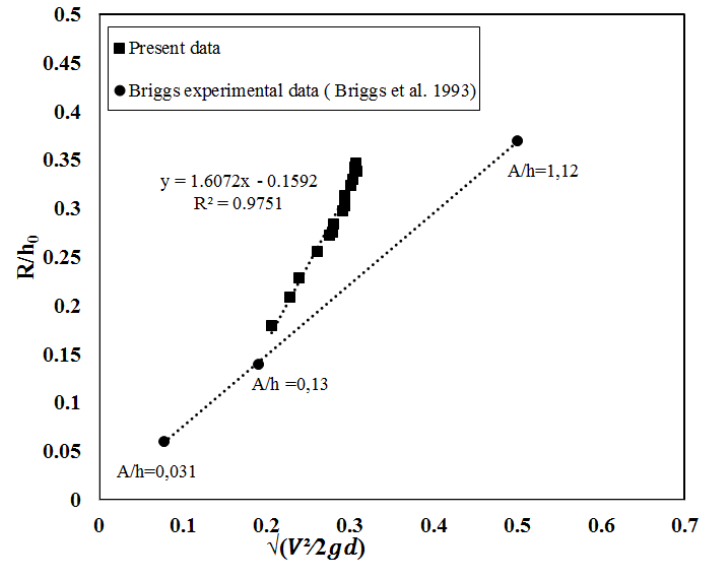

Figure 16. Runup velocity evolution

\section{Discussion and Conclusions}

Variations in wave characteristics for solitary wave in shallower are discussed in this paper. The behavior of the solitary wave above a flat bottom and a sloping bottom is given. We find that the energetic dissipation of the solitary wave on the flat bottom is related to the non-linearity parameter $\varepsilon$ '. In term of energetic intensity, low and high frequency components due to the waves generation mode are negligible when compared to the component of the excitation frequency of solitary waves. It is found that experimental results are in good agreement with the literature. The present study on the propagation of individual solitary waves representing the main component of a tsunami waveform should be extended to include other experimental generation mode. Future research needs to be focused on laboratory investigations of waveforms composed of group focused waves. The challenge is to compare these two types of generation.

\section{Reference}

Boussinesq, M. H. 1871. “Théorie de l'intumescence liquide, appelée onde solitaire ou de translation,se propageant dans un canal rectangulaire", C. - R. Acad. Sci. Paris, 72p.

Briggs.J.M.1993." Laboratory measurements of Tsunami Run-up", Conference: IUGG/IO International Tsunami '93 Symposium, At Wakayama, Japan. Volume: 1.

Camfield, F. E. and Street, R. L. 1969. "Shoaling of solitary waves on small slopes", Journal of Waterway and Harbor Division, ASCE, 1, 122.

Chang, L., Yeh, P. H., Hsieh, S. C., Shih, Y. N., Lo, L. F. and Tsai, C. P. 2014. "Prebreaking internal velocity field induced by a solitary wave propagating over a 1:10 slope", Ocean Engineering 80 (2014), 1-12.

Daily, J. W. and Stephan, S. C. 1952. "The solitary

wave: its celerity, profile, internal velocities and amplitude attenuation in a horizontal smooth channel", Proceedings of $3^{\text {rd }}$ Conference of Coastal Engineering, 13-30.

Goring, D. G. 1979. "Tsunami-the propagation of long waves onto a shelf", $\mathrm{PhD}$ thesis, California Institute of Technology, Pasadena, Calif.

Grilli, S. T., Svendsen, I. A. and Subramanya, R. 1997. "Breaking criterion and characteristics for solitary waves on slopes", Journal of waterway, Port, Coastal, and Ocean Engineering, 123(3), 102-112.

Hafsteinsson, J.H., Evers, M.F. and Hager, H. 2017." Solitary wave run-up: wave breaking and bore propagation", Journal of Hydraulic Research Vol.55, No. 6, pp. 787-798.

Hsiao, S. C. and Lin, T. C. 2010.” Tsunami-like solitary waves impinging and overtopping an impermeable seawall: Experiment and RANS modeling", Journal of Coastal Engineering, Volume 57, Issue 1, Pages 1-18.

Hsiao, S. C., Lin, T. C. and Chang, Y. H. 2008. "On the evolution and run-up of breaking solitary waves on a mild sloping beach", Coastal engineering 55(12):975-988.

Hughes, S.A. 2004. "Estimation of wave run-up on smooth, impermeable slopes using the wave momentum flux parameter", Coastal Engineering. 51, 1085-1104.

Ippen, A.T. and Kulin, G. 1954. "The shoaling and breaking of the solitary wave", Coastal Engineering Proceedings.

Keulegan, G. H. (1948).” Gradual damping of solitary waves", Part of the Journal of Research of the National Bureau of Standards, 40, 487498.

Kharif, C. and Pelinovsky, E. 2003. "Physical mechanisms of the rogue wave phenomenon, European J. Mechanics B, 22, 603-635.

Kishi, T. and Saeki, H. 1966. "The shoaling, breaking and runup of the solitary wave on impermeable rough slopes", Proceedings of the $10^{\text {th }}$ Conference on Coastal Engineering, I, 322-348.

Li, Y. and Raichlen. 2001."Solitary wave runup on plane slopes", Journal of Waterway, Port, Coastal, and Ocean Engineering, Vol. 127, Issue 1. 
Li, Y. and Raichlen. 2002." Non-breaking and breaking solitary wave runup", Journal of Fluid Mechanics, vol.456, pp. 295-318

Marin, F., Abcha, N., Brossard, J. and Ezersky, A. B. 2005. "Laboratory study of sand bedforms induced by solitary waves in shallow water", J. Geophys. Res. 110, F4.

Strusińska-Correia, A. and Oumeraci, H (2012)." Nonlinear Behavior of Tsunami-Like Solitary wave over Submerged Impermeable Structures of Finite Width", Coastal Engineering Proceedings, icce.v33.Currents.6

Orszaghova, J., Taylor, H., P, Alistair G.L., Borthwick. And Raby, A.C. 2014. "Importance of second-order wave generation for focused wave group run-up and overtopping", Journal of Coastal Engineering. 94(2014) 63-79.

Russel, J.S. 1845. "Report on waves", in proc. $14^{\text {th }}$ Meeting. Brit. Ass. Adv., 1845. Pp.311-390

Synolakis, C.E. 1987. "The runup of solitary waves", Journal of Fluid Mechanics, volume 185 , pp. 523-543

Synolakis, C.E. 1991. "Green's law and the evolution of solitary waves", journal of Physics of

Fluids A: Fluid Dynamics, Volume 3, Issue 3, p.490-491

Synolakis, C. E. and Skjelbreia, J. E. 1993." Evolution of Maximum Amplitude of Solitary waves on Plane Beaches", Journal of Waterway, Port, Coastal, and Ocean Engineering, 119(3), 323-342.

Tian, Z., Perlin, M., and Choi, W. 2010. "Energy dissipation in two-dimensional unsteady plunging breakers and eddy viscosity model", Journal of Fluid Mechanics., 655, 217-257, 2010 .

Yasuda, T., Sakakibara, Y. and Hara, M. 1992," BIM simulation on deformation up to breaking of solitary waves over uneven to bottoms" Proc, $4^{\text {th }}$ Int conf. on Hydr. Engrg. Software, Fluid Flow Modelling, W. R. Blain and E. Cabrera, eds., Elsevier, Southampton, U.K., 523-535.

Zelt, J. A. 1991." The runup of nonbreaking and breaking solitary wave", Coastal Engineering, 15(3), 205-246.

Zhang, C. and Wang, Y. 2010. "Determination of wave energy dissipation factor and numerical simulation of wave height in the surf zone", Ocean Engineering,pp. 1083-1092.

\section{List of figure}

Figure 1. Sketch of the experimental setup ............ 2 Figure 2. Comparison between theoretical and experimental solitary wave form............................ 3 Figure 4. Zoom on the main solitary wave; $\mathrm{A}_{0} / \mathrm{h}_{0}=0.28$ (13 $\mathrm{m}$ up to $16.7 \mathrm{~m}$ from the wave maker) ........................................................... 3 Figure 5. Evolution of the solitary wave $\left(\mathrm{A}_{0} / \mathrm{h}_{0}=0.28\right)$ with time: instantaneous signals at different distances from the wave maker; $a: 6 m$; : $8 \mathrm{~m}$; c: $10 \mathrm{~m}$; e: $12 \mathrm{~m}$; f: $14 \mathrm{~m} . . . \ldots \ldots \ldots \ldots \ldots \ldots \ldots \ldots \ldots . . . . . . . . . . . . . . . .3$ Figure 3. Comparison between theoretical (Eq. 2) and experimental solitary wave velocities ............. 3 Figure 6. Amplitude evolution on the slope for $\boldsymbol{\varepsilon}^{\prime}=\mathrm{At} / \mathrm{h} 0=0.26$ and comparisons with Green's Law4 Figure 7. Zoom on the spectrogram of complete solitary wave signal (6 $\mathrm{m}$ up to $16.7 \mathrm{~m}$ from the wave maker); $\mathrm{A} 0 / \mathrm{h}=0.28$ (a.u: arbitrary units)...... 5 Figure 8 . Variation of the amplitude dissipation factor with $\varepsilon=\mathrm{A}_{0} / \mathrm{h}_{0}$ on the flat bottom (from $3 \mathrm{~m}$ up to $9.5 \mathrm{~m})$

5

Figure 10. Variation of the breaking height with $\varepsilon^{\prime} 6$ Figure 11. Breaking distance evolution with $\boldsymbol{\varepsilon}^{\prime}$..... 6 Figure 9. Snapshots of a plunging breaking for a

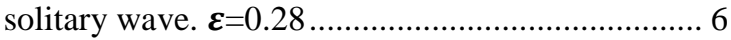
Figure 12. Normalized runup variation with $\varepsilon$ '..... 6 Figure 13. Maximal run-up amplitude comparisons with equation 13 and equation 14 7 Figure 14. Runup evolution versus dimensionless time for 4 different waves $(t *=\operatorname{tgh} 0)$................. 7 Figure 15. Dimensionless time of runup saturation

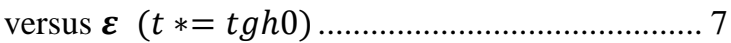
Figure 16. Runup velocity evolution...................... 8 